\title{
POR UM OUTRO PRINCÍPIO DE REALIDADE: NOVOS LUGARES E MOTIVOS SOCIAIS DA NEGAÇÃO SEGUNDO HERBERT MARCUSE
}

\author{
Rosalvo Shutz*
}

\begin{abstract}
RESUMO
Segundo Marcuse, a identificação do proletariado industrial como sendo o único sujeito de transformações sociais efetivas no capitalismo não se coaduna mais com a realidade. Essa convicção o levou a buscar ampliar o próprio conceito de negação herdado da tradição marxiana. Apoiado e superando a teoria freudiana do "princípio de realidade", Marcuse desenvolveu uma teoria de transformação social baseada em aspectos qualitativos, centrados na capacidade de subsidiar novos princípios de realidade que não o capitalista. Julgou encontrar alguns desses aspectos potencialmente revolucionários em temas como a sensibilidade, a estética, os movimentos sociais e na transformação radical das próprias necessidades e aspirações.
\end{abstract}

Palavras-chave: Princípio de desempenho. Mudança qualitativa. Reabilitação instintiva.

\begin{abstract}
In accordance with Marcuse, the industrial proletariat identification as the only subject of effective social transformations in capitalism does not correspond with the reality. This conviction took him to magnify his own negation concept inherited from Marx's tradition. He supported and overcame Freud's reality principle theory; Marcuse developed a social transformation theory based on qualitative aspects, centered in the ability to subside new reality principles other than the capitalism. He was judged to find some of these aspects potentially revolutionary in themes such as
\end{abstract}

\footnotetext{
* Doutor em Filosofia pela Universidade de Kassel (Alemanha). Professor no Centro de Ciências Humanas e Sociais - Filosofia, da Universidade Estadual do Oeste do Paraná (UEOP). E-mail: rosalvoschutz@hotmail.com
} 
sensibility, esthetics, social movements and in the radical transformations of his own necessities and aspirations.

Keywords: Performance principle. Qualitative change. Instinctive rehabilitation.

\section{Introdução}

Herbert Marcuse esteve diretamente envolvido em muitos movimentos e processos de transformação em sua época. Diferentemente da maioria de seus colegas da Escola de Frankfurt, seu engajamento junto a movimentos sociais foi decisivo em sua trajetória intelectual. Isso, no entanto, não significou que defendesse posições dogmáticas marcadas pelo DIAMAT (DialektischeMaterialismus) soviético. A insatisfação de Marcuse diante de certas posições no que diz respeito aos possíveis processos de transformação o levou a fazer reflexões e a sugerir ações bastante peculiares. Contra uma posição, por exemplo, que via no proletariado industrial o único sujeito revolucionário, chega a concluir incisivamente: “[...] a classe trabalhadora ainda é a portadora histórica da revolução; por meio de sua participação nas necessidades estabilizadoras do sistema, ela, no entanto, se tornou uma força conservadora e até mesmo contrarrevolucionária" (MARCUSE, 1969, p. 33)ํ. Para Marcuse, aceitar essa realidade de forma alguma significa negar as relações de exploração do capitalismo, mas, sim, aceitar que o capitalismo é capaz de aprimorar as suas formas de exploração: "O capitalismo se reproduz na medida em que se transforma, e esta transformação consiste primordialmente em aprimorar a exploração" (1969, p. 29). O apego a conceitos com significados petrificados herdados de uma tradição enrijecida seria um dos maiores impedimentos para entender a realidade atual e, por isso, de perceber as possibilidades de negação realmente existentes: "A petrificação (Vedinglichung) de conceitos falsifica a análise da estrutura de classe do capitalismo de monopólio" (MARCUSE, 1973, p. 45).

\footnotetext{
1 A tradução das citações desta obra (1969) é feita por nós a partir da versão em língua alemã.
} 
Propõe, nesse sentido, que o conceito de classe seja repensado e ampliado. Essa mudança, no entanto, não seria uma mudança arbitrária, e sim baseada na "[...] mudança na realidade do capitalismo que tem de ser conceptualizada na teoria do capitalismo" (MARCUSE, 1973, p. 46). Atualmente é inegável que, apesar de existirem condições objetivas que poderiam pôr fim ao capitalismo (existe "riqueza social suficiente para abolir a pobreza; os conhecimentos técnicos para desenvolver, em bases práticas e sistemáticas, os recursos existentes, visando a esse objetivo;" etc.), ao mesmo tempo a dinâmica capitalista parece estar ampliando o seu domínio: "[...] em todas as dimensões do trabalho e do lazer, controla a população subjacente, através dos bens e serviços que fornece e através da maquinaria política, militar e policial de assustadora eficiência" (MARCUSE, 1973, p. 16).

Segundo Marcuse (1973, p. 21), há que se considerar que a classe trabalhadora "[...] excede os limites da classe trabalhadora operária" (1973, p. 21). Isso se deve ao fato de que a base produtiva e, com isso, o próprio conceito de trabalho produtivo, e, consequentemente, o de trabalhador produtivo, foi enormemente ampliado na fase atual do capitalismo. Nas formas de trabalho cada vez mais socialmente combinadas tornouse mais explícito que mesmo aqueles trabalhadores não diretamente envolvidos no "chão de fábrica" também eles têm funções essenciais no processo produtivo, o que permite visualizar um universo ampliado de exploração. Os indivíduos são cada vez mais reduzidos a partes de um instrumento de exploração: "[...] ativo ou passivo, produtivo ou receptivo, nas horas de trabalho ou nas horas de lazer, ele[s] serve[m] ao sistema" (MARCUSE,1973, p. 22). Mesmo assim, no entanto, “[...] a separação do controle dos meios de produção define a condição objetiva comum dos que recebem salários e ordenado: a condição de exploração. Todos eles reproduzem capital" (MARCUSE, 1973, p. 24). Uma vez que todos reproduzem capital e são explorados, todos eles são potenciais lugares sociais de negação.

As constatações feitas levaram a concluir ser necessário "[...] não a revisão mas a restauração da teoria marxista: a sua emancipação do seu próprio fetichismo e ritualização, da retórica petrificada que sustou o seu desenvolvimento dialético" (MARCUSE, 1973, p. 37). Instigar o 
desenvolvimento dialético da teoria marxiana para Marcuse significa essencialmente evidenciar a "[...] contradição entre aquilo que é e aquilo que é possível e deveria ser [...]” (MARCUSE, 1973, p. 29). Essa capacidade de pensar de forma negativa em relação ao que é, ou seja, "[...] orientado por um futuro, um futuro libertário, que está 'represado' na atualidade" (MARCUSE, 1969, p. 128) e que pode, portanto, interagir com a práxis, é o desafio filosófico que Marcuse vislumbra como forma de revitalizar o potencial crítico do próprio pensamento marxiano.

E foi no pensamento de Freud que Marcuse parece ter encontrado um dos maiores instrumentos/referências para desenvolver essa perspectiva de ampliação da perspectiva emancipatória, buscando, simultaneamente, ampliar tanto temática quanto socialmente as referências capazes de se contrapor à lógica da sociedade capitalista. Marcuse busca, apoiado de modo especial na teoria freudiana da contraposição entre princípio do prazer e princípio de realidade, afirmar que do que se trata de fato é de desenvolver um outro princípio de realidade que não o que rege a sociedade atual. Com essa perspectiva a ênfase de processos emancipatórios pôde ser direcionada muito mais aos aspectos qualitativos pelos quais um princípio de realidade se orienta. A busca de elementos para fundar um novo princípio de realidade passa, assim, a orientar a identificação do lugar social da negação.

Em Freud se justifica o caráter repressivo dos instintos pelo fato de esse autor pressupor um conflito irreconciliável entre o princípio do prazer e o princípio de realidade. Como os instintos básicos estariam sempre em busca do predomínio do prazer, a luta contra eles seria uma constante no interior da civilização: daí o constante e insuperável mal-estar na civilização. Para Freud, "[...] a civilização é construída sobre uma renúncia ao instinto [...] pressupõe exatamente a não-satisfação (pela opressão, repressão, ou algum outro meio?) de instintos poderosos" (FREUD, 1978, p. 157). Como os instintos básicos estariam sempre em busca do predomínio do prazer, a luta contra eles seria uma constante no interior da civilização: daí o constante mal-estar na civilização, já que privar um instinto de sua satisfação é, segundo Freud (1978, p. 157), algo que "não se faz impunemente" (1978, p. 157). Ao final das contas, no entanto, para Freud é das energias vitais daí advindas e sublimadas para a civilização (através, por exemplo, do 
trabalho, da arte, da ciência, etc.) que esta se viabiliza. Assim, repressão instintiva e civilização estão intimamente imbricadas na teoria freudiana e isso ao ponto de a repressão ter se interiorizado nos próprios indivíduos de forma a, por exemplo, conseguir dominar, através do sentimento de culpa, "[...] o desejo de agressão do indivíduo, enfraquecendo-o, desarmando-o e estabelecendo no seu interior um agente para cuidar dele, como uma guarnição numa cidade conquistada" (FREUD, 1978, p. 177), ou, na leitura que Marcuse faz da teoria freudiana, “[...] a repressão externa foi sempre apoiada pela repressão interna: o indivíduo escravizado introjeta seus senhores e suas ordens no próprio aparelho mental" (MARCUSE, 1999, p. 37). A tensão entre ego e superego é a expressão dessa contradição e, por isso '[...] Freud considera 'eterna' a 'luta primordial pela existência' e, portanto, acredita que o princípio do prazer e o princípio realidade são 'eternamente' antagônicos" (MARCUSE, 1999, p. 37).

Além disso, segundo Marcuse, Freud não teria feito uma diferenciação adequada entre as "vicissitudes biológicas e as históricosociais", permitindo que sua teoria se torne facilmente instrumentalizável para a justificação ideológica de sacrifícios e de opressões. Muito facilmente todas as formas de repressão aparecem como supostos sacrifícios necessários em vista da civilização. Freud não pôde perceber que uma certa racionalidade da dominação foi mantida e "modelada pelo interesse de dominação" e que é "[...] exercida por um determinado grupo ou indivíduo, a fim de se manter e consolidar numa posição privilegiada" (MARCUSE, 1999, p. 53). Na medida em que os conceitos freudianos estão carregados de um caráter não histórico, sua teoria não permitiria a distinção entre a repressão instintiva necessária e aquela instrumentalizada. Dessa forma, ela estaria, portanto, contribuindo para a naturalização dos conteúdos repressivos de uma realidade específica, histórica e socialmente constituída. Uma realidade repressiva específica poderia aparecer enquanto representante do próprio princípio de realidade enquanto tal, não percebendo a repressão excessiva (mais-repressão) que eventualmente poderia existir ${ }^{2}$ a serviço de interesses de dominação. Para superar essa

2 Mesmo acrescentando criticamente um caráter histórico e social à teoria de Freud, Marcuse (1999, p. 50) não nega a intuição fundamental de Freud: "O princípio de realidade 
possível coisificação da teoria freudiana, Marcuse propõe uma apropriação positiva e simultaneamente crítica dessa mesma teoria.

Para Marcuse, o princípio de realidade na atualidade estaria se manifestando em uma forma histórica específica e que, portanto, poderia e deveria ser modificado, uma vez que "[...] o indivíduo ainda é castigado por impulsos que foram dominados há muito tempo e feitos que há muito se resolveram" (MARCUSE, 1999, p. 69). Vejamos suas diferenciações: a) distinção entre repressão básica e mais-repressão: "Mais-Repressão: as restrições requeridas pela dominação social. Distingue-se da repressão (básica): as 'modalidades' dos instintos necessários à perpetuação da raça humana em civilização"; b) distinção entre princípio de realidade e princípio de desempenho: "Princípio de Desempenho: a forma histórica [atualmente] predominante do princípio de realidade" (MARCUSE, 1999, p. 51). Sendo que o princípio de desempenho é apresentado, falaciosamente, como sendo o princípio de realidade.

Diante da posição alcançada em relação a teoria freudiana, os esforços de Marcuse passam a concentrar-se na busca de elementos, espaços e valores que possam se contrapor ao princípio de desempenho, identificado com o princípio específico que rege a própria sociedade capitalista. Sua convicção básica é a de que, da “[...] necessidade histórica do princípio do desempenho e da sua perpetuação, para além da necessidade histórica, não se segue que seja impossível outra forma de civilização, sob outro princípio de realidade" (MARCUSE, 1999, p. 137). Pelo contrário, é na busca de elementos para fundamentar outro princípio que se constituem os valores e locais sociais da negação. Conforme afirma em seu texto Cultura e psicanálise, "[...] é preciso que um princípio de realidade qualitativamente diferente substitua o princípio de realidade repressivo, trazendo consigo uma mudança radical no plano psíquico, assim como no próprio plano histórico-social" (MARCUSE, 2004, p. 116).

O critério para identificar o lugar social da negação, portanto, passa a ser um critério qualitativo, uma vez que se trata de buscar subsídios para fundamentar/legitimar um outro princípio de realidade: "Somente

ampara o organismo no mundo externo. [...] uma organização repressiva dos instintos é subjacente a todas as formas históricas do princípio de realidade na civilização" (1999, p. $50)$. 
a mudança qualitativa é mudança, e a nova qualidade de vida é a única que pode acabar com uma longa série de sociedades exploradoras" (MARCUSE, 1973, p. 40). Essa posição teórica em relação à teoria freudiana contribuiu para fortalecer a convicção de Marcuse de que é preciso buscar elementos para além da realidade que nos é apresentada como sendo a totalidade (SCHÜTZ, 2009; 2012). Marcuse resume todas as formas de protesto contra as formas de repressão desnecessárias com o termo "Grande Recusa". A teoria expressa nesse termo está perfeitamente compatível com o horizonte de reflexão mais amplo e segundo o qual, com a modificação da estrutura do capitalismo, modificou-se também a base para o desenvolvimento e a organização de potenciais forças revolucionárias. Diga-se, no entanto, que a negação do princípio do desempenho não implicaria uma contradição com o progresso, mas, sim, a "mais alta maturidade da civilização" (MARCUSE, 1999, p. 139), capaz, inclusive, de libertar as dimensões eróticas bloqueadas e reprimidas no interior da realidade regida por esse princípio. Indicam para esse potencial exemplos como: (i) a redução da jornada de trabalho, uma vez que a atual duração do dia de trabalho é considerada por Marcuse como um dos "principais fatores repressivos impostos ao princípio de prazer” (1999, p. 141); (ii) a libertação de Eros que, no princípio de desempenho, foi confinado/confundido com a sua dimensão sexual e até mesmo genital; (iii) o "re-estabelecimento" de uma relação produtiva e complementar com a natureza, atualmente reduzida a simples material à disposição de projetos humanos concebidos no horizonte do princípio de desempenho; (iv) a recuperação do caráter revolucionário da dimensão estética (arte pela arte) atualmente reduzida a clichês que servem à indústria cultural; dentre outros exemplos.

Essa postura crítica, que, evidentemente, implica uma ampliação da base e dos "motivos" da revolução, aponta, simultaneamente, para além da teoria socialista tradicional. Ou, conforme afirmação do próprio autor: "[...] o deslocamento do lugar das forças negativas e de sua referência tradicional pode apontar para a formação de uma nova base, na qual um novo sujeito da mudança pode vir à tona, o qual poderá reagir a novas condições com necessidades qualitativamente diferenciadas" (MARCUSE, 1969, p. 81-82). Ao deslocar o lugar social da negação, Marcuse desloca e amplia o lugar social da emancipação, priorizando a busca e a construção 
de elementos qualitativos, capazes de fundamentar um outro princípio de realidade que não o princípio de desempenho. Aponta, assim, para os potenciais emancipatórios daquelas dimensões e daqueles movimentos sociais que dão expressão a diferenças e a contradições qualitativamente novas em relação à totalidade existente. As consequências dessa concepção para a práxis política e social são evidentes: o proletariado perde a centralidade revolucionária e os movimentos sociais e a busca e a satisfação de novas necessidades - baseadas numa nova sensibilidade adquirem importância e legitimidade antes não consideradas: "A dinâmica interna do capitalismo muda, com as transformações em sua estrutura, o padrão da revolução: longe de reduzir, amplia a base potencial de massa para a revolução e necessita do renascimento de metas mais radicais do que mínimas do socialismo" (MARCUSE, 1973, p. 14).

\section{Novos temas: sensibilidade, necessidades e estética}

Coerente com suas análises, Marcuse afirma, em seu texto Natureza e revolução:

A ênfase marxista sobre o desenvolvimento econômico da consciência política mostra escasso interesse pelas raízes das relações sociais aí onde os indivíduos mais direta e profundamente experimentam seu mundo e a si próprio: em sua sensibilidade, em suas necessidades instintivas (1973, p. 66).

Conclui, por isso, que, se "[...] este sistema de vida letal deve ser transformado, sem ser substituído por um igualmente letal, os seres humanos têm de aprender a desenvolver uma nova sensibilidade" (MARCUSE, 1969, p. 65). Assim, portanto, uma outra sociedade, regida por um outro princípio de realidade, terá de se desenvolver baseada em "[...] outras necessidades instintivas, outras reações do corpo e do espírito" (MARCUSE, 1969, p. 34). Isso implica dizer que os "[...] próprios indivíduos devem mudar seus próprios sentidos, instintos e sensibilidades se quiserem construir, em associação, uma sociedade qualitativamente diferente" (MARCUSE, 1973, p. 76), ou seja, se quiserem construir uma sociedade, por isso, liberta da produtividade destrutiva da sociedade exploradora. 
A centralidade das questões qualitativamente diferentes desde sua origem baliza todas as reflexões sociais e políticas de Marcuse. Os sentidos, que, na história do pensamento ocidental, de modo geral, recebem uma função demasiadamente passiva ou então puramente instrumental, aqui são abordados por Marcuse (1973, p. 66) de modo diferenciado: "Os sentidos não são meramente passivos, receptivos; eles têm suas próprias 'sínteses', às quais submetem os dados primários da experiência”. Ou seja, Marcuse atribui aos próprios sentidos um caráter constitutivo e histórico, de modo que também eles podem contribuir tanto num processo libertário quanto alienador.

Percebe-se, nas posturas teóricas do autor, a tentativa de superar o paradigma iluminista que visualiza toda e qualquer possibilidade emancipatória com base exclusiva na razão. As reflexões acima apontadas sobre os sentidos levam o autor a refletir criticamente também o próprio conceito de razão, esta geralmente percebida como contraposta e em oposição aos sentidos: "A razão é a racionalidade do princípio de desempenho. [...] um instrumento de coação, de supressão dos instintos. [...] tudo o que pertencer à esfera da sensualidade, do prazer, dos impulsos [...] tem de ser subjugado, reprimido" (MARCUSE, 1999, p. 146). A superação do princípio do desempenho, portanto, implica, para Marcuse, também a superação da atual concepção de razão, construída à custa dos sacrifícios e domínio dos sentidos. Mesmo assim, no entanto, essa concepção de razão tem suas origens anteriores ao próprio capitalismo: "Quando a Filosofia concebeu a essência do ser como Logos, é já o Logos da dominação imperativo, dominador, orientando a razão, à qual o homem e a natureza têm de estar sujeitos" (MARCUSE, 1999, p. 118). Como consequência, consolidou-se uma postura hostil em relação à natureza (tanto a humana como a não humana) e uma concepção de natureza que "foi dada" ao "ego como algo que tinha de ser combatido, conquistado e até violado; era essa a precondição da autopreservação e do autodesenvolvimento" (MARCUSE, 1999, p. 107). Num mundo alienado, a libertação de Eros poderia significar, portanto, a negação de um princípio repressivo, a negação de uma realidade legitimada pela sua suposta superioridade racional. 
Mesmo estando consciente da dificuldade de se gerar uma nova sensibilidade em um mundo alienado, a constatação de Marcuse parece inegável:

[...] a sociedade existente é reproduzida não só na mente, na consciência do homem, mas também nos seus sentidos; e nenhuma persuasão, nenhuma teoria, nenhuma argumentação, pode romper essa prisão, a menos que a sensibilidade fixa, petrificada, dos indivíduos seja 'dissolvida', aberta a uma nova dimensão da história (MARCUSE, 1973, p. 74).

A busca dessa nova sociedade, baseada em outro princípio de realidade, certamente não é algo que irá acontecer por decreto ou pela simples tomada de poder de um grupo ou partido. O critério para o caráter emancipatório de um agir, segundo nosso autor, não pode estar orientado apenas nos supostos fins almejados. Marcuse (1973, p. 55) aponta para uma processualidade na qual "as imagens e valores de uma futura sociedade livre devem aparecer nas relações pessoais dentro da uma sociedade nãolivre", ainda que uma sociedade livre não possa acontecer de forma plena no interior da sociedade estabelecida, já que "a liberdade em relação à dominação da mercadoria sobre a humanidade é uma condição prévia para a liberdade" (MARCUSE, 1969, p. 133).

A postura crítica de Marcuse em relação à amplitude emancipatória da razão, no entanto, não significa o abandono dos potenciais inerentes à razão. Significa apenas a necessidade de se repensar a própria concepção de razão, esta que, nos horizontes do princípio de desempenho, é considerada irreconciliável com a sensibilidade. Importante é que tanto os sentidos quanto a razão e a consciência precisam ser emancipados. Para o autor, "[...] a emancipação dos sentidos deve acompanhar a emancipação da consciência, envolvendo assim a totalidade da existência humana" (MARCUSE, 1973, p. 76).

A concepção de liberdade ocidental, baseada na capacidade de domínio sobre os sentidos, passaria, assim, a ser concebida enquanto enraizada na própria sensibilidade: "A emancipação dos sentidos faria da liberdade o que ela ainda não é: uma necessidade sensória, um objetivo 
dos Instintos de Vida (Eros)" (MARCUSE, 1973, p. 74). Libertar a liberdade bloqueada, no entanto, exige a construção de novas instituições: necessidades e satisfações antagônicas à sociedade exploradora. Essas instituições poderiam vir a ser, talvez, a base pulsional ('triebmässige' Basis) para a realização dessa liberdade bloqueada. Isso exigiria, por exemplo, tornar os nossos sentidos (olhar, ouvir, sentir...) receptivos para formas não agressivas e não exploradoras do mundo. Exigiria, também, o desenvolvimento de uma nova qualidade tecnológica e científica chamada por Marcuse de "tecnologia da libertação" (1969, p. 37), que, no entanto, provavelmente só seria possível enquanto expressão de um novo tipo humano (Menschentyps) capaz de experimentar as coisas para além da interrelação de exploração e violência. Uma harmonia entre uma consciência radical e a sensibilidade, que estivesse para além da simples oposição entre razão e sensibilidade e que teria, então, a possibilidade de gerar uma razão sensível, na qual o ser humano pudesse perceber-se enquanto "jardineiro do mundo" (contribuindo para desenvolver o que há de melhor na própria natureza) e não mais apenas como um senhor dominador.

\section{Outras necessidades}

A concepção até aqui exposta está orientada pela busca de uma contraposição qualitativa com as tendências de produção e consumo do capitalismo avançado marcado pela "[...] crescente necessidade de produzir e consumir coisas não necessárias” (MARCUSE, 1969, p. 78). Essa tendência, por ela mesma, acaba fortalecendo uma sociedade repressiva e enfraquecendo as possibilidades de libertação. O desafio é se libertar das

[...] necessidades que eternizam a dependência em relação ao sistema. Sem esta ruptura, a qual só pode se tornar possível enquanto resultado do agir e da formação política, as forças rebeldes mais elementares podem ser abatidas ou então convertidas em massas de base da contrarrevolução (MARCUSE, 1969, p. 88).

Apesar de a legitimidade do sistema atual estar baseado fortemente na ideia da liberdade e da livre escolha (liberdade de consumo), ela produz, 
“[...] sobretudo, uma satisfação 'guiada' das necessidades materiais: [...] por trás do véu político da democracia, surge a realidade, a servidão universal, a perda da dignidade humana em uma liberdade de escolha pré-fabricada" (MARCUSE, 1973, p. 23). Uma outra sociedade deveria, portanto, modificar também os padrões qualitativos, tanto das formas e dos padrões de atuação política, quanto das necessidades e das satisfações da sociedade atual: "Mas o que está em jogo [...] não é, meramente, a ampliação da satisfação dentro do universo existente de necessidades [...] mas o rompimento com esse universo, o salto qualitativo". Há que se ter vista a uma "[...] transformação radical das próprias necessidades e aspirações, tanto culturais como materiais; da consciência e da sensibilidade; do processo de trabalho e do lazer" (MARCUSE, 1973, p. 25).

Com Marcuse pode-se afirmar, portanto, que os padrões e as possibilidades de um processo de transformação na atualidade foram enormemente ampliados, mas que, para tanto, há que se buscar critérios e práticas qualitativamente diferenciadas daquelas regidas pelo princípio do desempenho, capazes de gerar necessidades que transcendam inclusive os padrões de satisfação e de atuação política atualmente vigentes. Há que se buscar novas necessidades e que podem estar baseadas e ser impulsionadas também pelas próprias necessidades impulsivas atualmente reprimidas. Nesse sentido, pode se dizer, por exemplo, que Marcuse busca visualizar uma espécie de "fundamento impulsivo psicológico" (1969, p. 25) ou mesmo biológico para a solidariedade, desde que se entenda por necessidade biológica aquelas necessidades "[...] que têm de ser satisfeitas e para as quais não pode ser criado um substituto adequado" (MARCUSE, 1969, p. 25). Segundo nosso autor, a sociedade da economia consumista conseguiu instrumentalizar, de forma agressiva e libidinosa, essas necessidades reprimidas, na medida em que naturaliza determinadas normas sociais, tornando-as a base de normas orgânicas que passam a pré-formatar os próprios desejos. Essa esfera é como se fosse uma segunda natureza, ou seja, algo que transcende consciência e ideologia e introjeta modelos de relação e desejos na própria "natureza" dos seus integrantes. Assim, uma revolta que não consiga transformar essa "segunda natureza" não seria, segundo Marcuse, uma mudança completa, se é que poderá ser iniciada. Por isso a 
"[...] contrarrevolução está apoiada na estrutura instintiva" (MARCUSE, 1969, p. 27). Assim seria possível progredir “[...] rumo a uma nova etapa da civilização, na qual o ser humano tenha aprendido a perguntar para quem e para quê a sua sociedade está organizada" (MARCUSE, 1969, p. 132).

A dimensão estética também sempre recebeu grande importância no pensamento de Marcuse. Em contraposição ao princípio de realidade repressivo, “[...] a reconciliação estética implica um fortalecimento da sensualidade, contra a tirania da razão, e, em última instância, exige até a libertação da sensualidade, frente à dominação repressiva da razão" (MARCUSE, 1999, p. 161). A dimensão estética é vista, portanto, como portadora da possibilidade de trazer à tona e expressar aquilo que, no horizonte do princípio de realidade vigente, não pode ser expresso: é reprimido. Assim, “[...] a 'linguagem' da arte partilha uma objetividade que a linguagem comum e as experiências comuns não conseguem alcançar" (MARCUSE, 1969, p. 66). Por isso, estética e política têm uma unidade intrínseca no pensamento de nosso autor, já que “[...] a repressão das necessidades estéticas e morais é um veículo de dominação" (MARCUSE, 1973, p. 26). Ela tem uma função importantíssima, principalmente na medida em que denuncia a distância entre promessa e realidade e na medida em que "[...] está comprometida numa emancipação da sensibilidade, da imaginação e da razão em todas as esferas da subjetividade e da objetividade" (MARCUSE, 1977, p. 22). A ligação entre estética e política em Marcuse sugere, inclusive, uma nova compreensão do materialismo dialético, demasiadamente aprisionado a esquematismos prévios e a conceitos petrificados: "A imaginação, como conhecimento, retém a insolúvel tensão entre ideia e realidade, o potencial e o real. É este o núcleo idealista do materialismo dialético: a transcendência da liberdade, para além das formas dadas" (MARCUSE, 1973, p. 73). Segundo convicção de Marcuse, a “[ [...] lógica interna da obra de arte termina na emergência da outra razão, outra sensibilidade, que desafiam a racionalidade e a sensibilidade incorporadas nas instituições sociais dominantes” (1977, p. 20). Por isso, “[...] a arte representa o objetivo derradeiro de todas as revoluções: a liberdade e a felicidade do indivíduo" (MARCUSE, 1977, p. 75). 


\section{Novos sujeitos sociais: que ainda não foram atingidos ou já superaram o princípio de desempenho}

A suspeita, levantada por Marcuse, é de que o horizonte de transformação tradicional, baseado em uma perspectiva puramente imanente, acaba aprisionando a práxis social ao interior dos sistemas, ao dogma idealista do inevitável progresso da razão e da história. Ações desenvolvidas dentro desse horizonte seriam facilmente neutralizadas e catalisadas pela própria totalidade existente. Nesse sentido, portanto, o autor busca apontar sempre para a necessidade de se compreender a possibilidade de negação da negação para além das contradições internas de uma totalidade. Para tanto, seria necessário atentar para necessidades objetivas simplesmente reprimidas pela totalidade antagônica existente. Essas necessidades estariam baseadas em forças e em movimentos que ainda não teriam sido manietados ou que já teriam se libertado do horizonte da produtividade agressiva e repressiva da sociedade moderna:

O poder de negação surge fora dessa totalidade repressiva, a partir de forças e movimentos que ainda não estão manietados pela produtividade agressiva e repressiva da chamada 'sociedade de abundância', ou que já se libertaram desse desenvolvimento (MARCUSE, 1972, p. 165).

Devido à integração progressiva da tradicional classe trabalhadora industrial ao sistema, "[...] os catalizadores da mudança se tornam atuantes 'desde fora"' (MARCUSE, 1969, p. 84). Isso ocorre porque, numa

[...] sociedade baseada no trabalho alienado [...] os homens só percebem as coisas nas formas e funções em que lhes são dadas, feitas, usadas pela sociedade existente; só percebem as possibilidades de transformação tal como são definidas e limitadas na sociedade existente (MARCUSE, 1973, p. 74).

A superação a ser buscada não é do trabalho em si, uma vez que este é constitutivo do ser humano na sua relação tanto com a natureza quanto com a sociedade e consigo mesmo. Marcuse sugere uma nova forma de satisfação "[...] sem labuta - isto é, sem o domínio do trabalho alienado sobre a existência humana" (1999, p. 141). A superação das formas de trabalho alienado e, portanto, do indivíduo burguês e suas exigências de 
desempenho, no entanto, não pode se dar de forma apenas individual. A libertação individual só pode acontecer de fato na medida em que vem acompanhada da libertação da sociedade e vice-versa. O grande desafio é conseguir fazer a contraposição a uma sociedade funcional e crescente, o que pode inclusive criar certo conflito com a "maioria trabalhadora bem integrada" (MARCUSE, 1969, p. 81). A tendência seria a de que as práticas políticas mais radicais se concentrem em grupos minoritários ${ }^{3}$. Marcuse, no entanto, está bem lúcido quanto aos limites, dificuldades e contradições a serem enfrentadas:

O que acontece é a formação de grupos relativamente ainda pequenos muitas vezes com uma organização fraca (muitas vezes desorganizada), mas que, devido à força de sua consciência e de suas necessidades, atuam como catalizadores da rebelião em meio à maioria, à qual pertencem conforme sua origem de classe $(1969$, p. 80$)$.

Percebe-se, portanto, que Marcuse busca superar uma ontologização dos sujeitos revolucionários, atribuindo-lhes um caráter histórico e dinâmico: "As forças revolucionárias surgem no próprio processo de transformação; a tradução do potencial em atualidade é o trabalho da práxis política" (1969, p. 117). A práxis política, portanto, não deveria ser confinada a esquematismos e fabricações prévias. Ela não pode mais se orientar em uma concepção de revolução formulada no final do século XIX e início do século XX. Essa concepção está já determinada no passado por um horizonte marcado pela "tomada do poder" por um levante das massas dirigida por um partido revolucionário que pressupunha uma vanguarda da classe revolucionária a qual iria introduzir as mudanças fundamentais da sociedade. No atual capitalismo avançado, onde as massas foram integradas e se tornaram, elas próprias, forças de conservação e estabilização, não se pode mais esperar que efetivem essa sua função idealmente concebida. Por isso “[...] os grupos minoritários de hoje, sobre os quais recairá a tarefa de

3 Ao apontar esse potencial, Marcuse não nega objetivamente o proletariado enquanto potencial classe revolucionária: "Evidentemente é algo sem sentido afirmar que a oposição civil substitui o proletariado enquanto classe revolucionária e de que o lumpemproletariado adquire uma força política radical". (1969, p. 80). 
organização, serão muito diferentes da vanguarda leninista" (MARCUSE, 1973, p. 47). O seu potencial estaria na sua consciência e objetivos que os tornam "[...] verdadeiros representantes dos interesses gerais dos oprimidos. [...] É a luta pela vida - por uma vida não de senhores nem de servos, mas de homens e mulheres" (MARCUSE, 1969, p. 81).

Essas posturas teóricas e políticas de Marcuse o levam a formular também uma crítica à democracia liberal-parlamentar: "Nas novas esquerdas disseminou-se uma significativa não aceitação das práticas políticas tradicionais [...] o que aponta para uma nova reconsideração da democracia [...] e de sua função rumo a uma sociedade livre" (1969, p. 97). Em vez de deixar que as aspirações da chamada nova esquerda se diluam, ou sejam, represadas na esfera da legalidade constituída, o que precisa ser evidenciado, segundo Marcuse, é uma contradição entre promessa e realidade da democracia existente, de forma que, se "[...] democracia significa o autogoverno de seres humanos livres e justiça para todos, então a realização da democracia pressuporia a superação da pseudo-democracia atualmente existente" (1969, p. 99). É evidente que uma luta contra essa pseudodemocracia, do ponto de vista dela mesma, provavelmente será considerada não democrática. O que teria de estar claro nesse caso, como afirma Marcuse no calor dos debates dos protestos estudantis do final dos anos 1960, é que a "[...] linguagem dominante de lei e ordem, que é declarada como válida pelos tribunais e pela polícia, não é apenas a voz mas a própria ação de opressão" (1969, p. 110). Nesse sentido, se poderia dizer que a luta de classes se dá, de fato, a partir dos "malditos desta terra" na medida em que estes se contrapõem ao status estabelecido. Por isso é que a "[...] análise crítica desta sociedade precisa de novas categorias: morais, políticas e estéticas” (MARCUSE, 1969, p. 21).

Segundo Marcuse, a oposição (o lugar social da negação) se evidencia em diversas formas e organizações. Cita, como exemplos, as rebeliões difusas entre os jovens e as dos intelectuais, bem como a luta cotidiana das minorias perseguidas:

O movimento estudantil não é, apesar de revolucionário em sua teoria, revolucionário em suas necessidades impulsivas e últimos objetivos 
[...] no entanto, ele é o fermento da esperança nas sufocantes superpoderosas metrópoles: ela testemunha a verdade da alternativa - a real necessidade e real possibilidade de uma sociedade livre (MARCUSE, 1969, p. 92).

O movimento de mulheres representa o potencial de negação de uma sociedade erigida a partir do princípio da produtividade destrutiva própria da forma mental e física da dominação masculina, que gera uma estrutura na qual "[...] nem homens nem mulheres são livres" (MARCUSE, 1973, p. 78). Por isso "[...] uma sociedade livre seria a 'negação definitiva' desse princípio - seria uma sociedade fêmea" (MARCUSE, 1973, p. 77) e por isso a luta do movimento feminino encontra sua radicalidade não na afirmação de uma sociedade matriarcal, transformando valores biológicos em éticos e culturais, mas na possibilidade “[...] ascendente de Eros sobre a agressão, em homens $e$ mulheres; [...] não só a igualdade dentro do emprego e da estrutura de valores da sociedade estabelecida (o que seria uma igualdade de desumanização), mas, antes, uma mudança na própria estrutura" (MARCUSE, 1973, p. 77). A superação da mais-agressão masculina se daria simultaneamente com a superação da mais-passividade feminina:

É da natureza das relações sexuais que ambos, macho e fêmea, sejam objeto e sujeito ao mesmo tempo; a energia erótica e a agressiva fundem-se em ambos. A mais-agressão do macho está socialmente condicionada - assim como a mais-passividade da fêmea (MARCUSE, 1973, p. 79).

As mulheres, no entanto, provavelmente teriam um potencial de contribuição maior do que os homens nesse processo, uma vez que o relativo "[...] isolamento (separação) do mundo do trabalho alienado do capitalismo habilitou a mulher a permanecer menos brutalizada pelo Princípio de Desempenho, a ficar mais fiel à sua sensibilidade: mais humana do que o homem" (MARCUSE, 1973, p. 80).

Como consequência política mais ampla dessas suas observações - aqui apenas sintética e exemplarmente indicadas por meio do movimento 
estudantil e de mulheres - Marcuse busca visualizar uma concepção política onde essas diversas formas de manifestação política seriam possíveis. Seria preciso, para tanto, reabilitar dimensões que, no processo de consolidação/instrumentalização da democracia, foram reprimidos. Uma dessas dimensões, possíveis de serem recuperadas e fortalecidas seria a de "[...] uma fecunda realização da tradição revolucionária, os 'conselhos' ('sovietes', Räte) como organização de autodeterminação e autogoverno (ou, melhor, de preparação para o autogoverno) nas assembleias populares locais" (MARCUSE, 1973, p. 50). Embora consciente da ambivalência e fragilidade dessa concepção (já que a "expressão imediata da opinião e vontade dos trabalhadores [...] não é, per se, progressiva nem uma força de mudança social; pode ser o oposto"), Marcuse insiste: "A democracia direta, a sujeição de toda a delegação de autoridade ao controle efetivo 'por baixo', é uma exigência essencial da estratégia da Esquerda" (1973, p. 51). Ou seja, a nova sociedade não pode ser resultado exclusivo de alguma teoria: deve antes acontecer enquanto obra livre de seres humanos libertos ou em processo de libertação. Trata-se de um processo que, apesar de não ser a realização de ideais impostos de fora, é marcado, desde o início, pelos seus objetivos.

\section{Considerações finais}

Ao apontar para a importância e primazia dos aspectos qualitativos necessários para fundamentar um novo princípio de realidade, que não o princípio de desempenho, Marcuse parece ter aberto um amplo horizonte de atuação e teorização. Na medida em que busca visualizar aquilo que é exterior ao sistema, aquilo, portanto, que ainda não foi ou já não é mais subsumido pela lógica da sociedade regida pelo princípio do desempenho, Marcuse revitaliza e atualiza o pressuposto básico da teoria crítica de Marx (1964, p. 86): o "[...] imperativo categórico de derrubar todas as condições em que o homem surge como um ser humilhado, escravizado, abandonado, desprezível". Da mesma forma que Marx (1964, p. 90) não pôde mais perceber na classe burguesa (em uma Alemanha que ainda não havia passado pela revolução burguesa - emancipação política) o potencial que 
dela faria "o representante negativo da sociedade", também Marcuse não percebe mais no operariado industrial esse representante. Mesmo ciente de que a simples substituição de um todo-parte por outro não implicaria necessariamente mudanças qualitativas na sociedade, Marcuse, no entanto, não abre mão da perspectiva dialética enfatizada por Marx: buscar o lugar social da negação. O diálogo produtivo e crítico com a teoria de Freud lhe permitiu fundamentar a necessidade da primazia qualitativa num processo de transformação.

A necessidade de atualização em cada contexto histórico e social determinado exige um esforço constante de apreensão e de potencialização daquelas qualidades e daqueles coletivos humanos que possam representar possíveis negações do princípio de realidade atualmente hegemônico. Certo, no entanto, é que nenhum sujeito, seja coletivo ou não, pode se dar o direito de ser automaticamente o portador do lugar social da negação. A importância da atuação e da práxis social e política que daí pode ser deduzida não é menor do que o desafio de conceber uma teoria capaz de se perceber integrada nessa processualidade, tornando constantemente consciente o possível: sem abdicar da autonomia mas também resistindo à tentação de enquadrar a realidade em conceitos prévios.

\section{Referências}

BRUKHORST, H.; KOCH, G. Herbert Marcuse: eine Einführung. Wiesbaden: Panorama, 2009.

FLEGO, Gvozden; SCHMIED-KOWARZIK, Wolfdietrich (Org.). Herbert Marcuse - Eros und Emanzipation. Murcuse - Symposion 1988 in Dubrovnik. Giessen: Germinal, 1989.

FREUD, Sigmund. O mal-estar na civilização. Tradução de J. Octávio A. Abreu. São Paulo: Abril Cultural, 1978 (Coleção Os Pensadores).

MARCUSE, Herbert. Cultura e psicanálise. Tradução de Wolfgang Leo Mar, Robespierre de Oliveira, Isabel Loureiro. Rio de Janeiro: Paz e Terra, 2004.

. Eros e civilização. Tradução deÁlvaro Cabral. 8. ed. Rio de Janeiro: LTC Editora, 1999. 
. Versuch überBefreiung. Frankfurtam Main: Suhrkamp, 1969. . Contra-revolução e revolta. Rio de Janeiro: Zahar, 1973. . Ideen zu einer kritischen Theorie der Gesellschaft. Frankfurt am Main: Suhrkamp, 1969a. . Kultur und Gesellschft I. Frankfurt am Main: Surkamp, 1968. . Vernunft und Revolution. Berlin: Luchterhand, 1970. . A ideologia da sociedade industrial: o homem unidimensional. Rio de Janeiro: Zahar Editores, 1978. . A dimensão estética. São Paulo: Martins Fones, 1977. . Ideias sobre uma teoria crítica da sociedade. Tradução de Fausto Guimarães. Rio de Janeiro: Zahar, 1972.

MARX, Carl. Manuscritos econômico-filosóficos. Lisboa: Edições 70, 1964.

SCHÜTZ, Rosalvo. O deslocamento do lugar social da negação em Herbert Marcuse. Argumentos - Revista de Filosofia, Fortaleza, n. 8, 2012. p. 188198.

- Sensibilidade emancipatória: Schelling, Feuerbach e Marx à contrapelo da tradição. In: CHAGAS, Eduardo; REDYSON, Deyve; PAULA, Márcio Gimenes de. (Org.). Homem e natureza em Ludwig Feuerbach. v. 08. Fortaleza: Edições UFC, 2009, p. 171-212.

Data de registro: 13/06/2012 Data de aceite:28/01/2013 